\section{The College of Microscopy - Meeting Rapidly Growing Microscopy Demands}

\author{
Donald A. Brooks \\ The McCrone Group, Westmont, Illinois \\ donbrooks@mccrone.com
}

The McCrone Group Inc. recently announced the completion of a 40,000 sq ft addition to house its new College of Microscopy. Since its founding in 1956, The McCrone Group has grown into a multi-faceted organization and now encompasses three main organizations, McCrone Associates - the analytical service and consulting firm; McCrone Microscopes \& Accessories - the microscope and instrument sales group; and, the College of Microscopy - the microscopy learning center. The newly completed addition houses the first and only College of Microscopy and offers the largest array of basic and advanced modern microscopy courses and analytical instrumentation within any single educational facility worldwide. At The McCrone Group, we have more than \$15 million worth of microscopes and analytical instrumentation and assembled one of the best scientific/ administrative teams in the world.

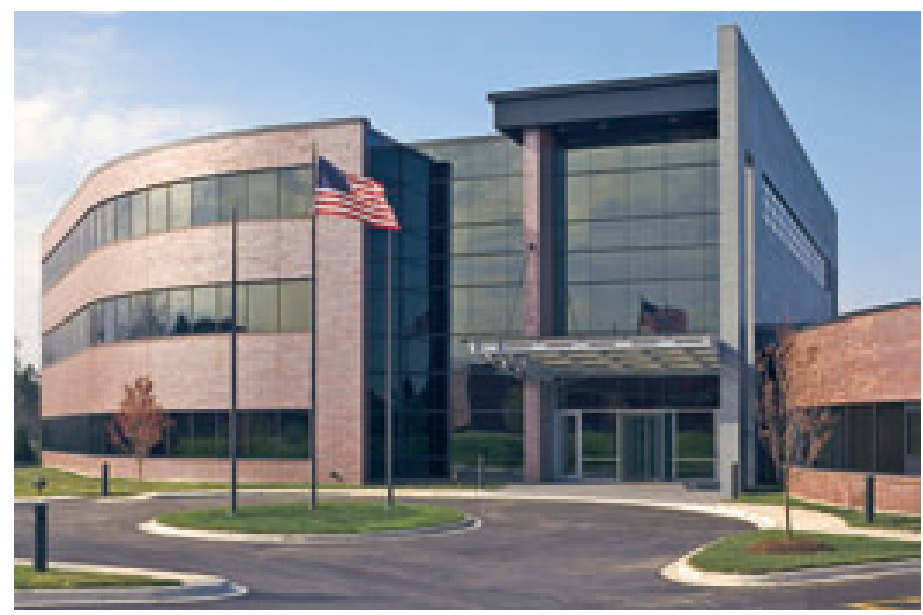

The College helps meet the growing need for microscopy as well as to educate microscopists of the future. With an offering of over 35 different courses being taught during 2007, the College prepares industry and government technicians and scientists to solve materials analysis problems. It also ensures that the skills and analytical capabilities of technicians, scientists, researchers, and science teachers continue to develop to the very highest levels.

The College of Microscopy specializes in training material scientists, crime lab personnel, first responders, researchers, technicians, and science teachers at all levels on how to locate, characterize, and identify unknown or suspect materials using light microscopy, electron microscopy, FTIR, and Raman spectroscopy. Many of the College of Microscopy instructors are internationally recognized experts in the field of materials analysis and microscopy. They offer a valuable and unique combination of theoretical and practical hands-on experience, and are esteemed for their expert laboratory analyses and broad discipline coverage. The staff of The McCrone Group has been teaching technicians, scientists, and researchers for more than 45 years.

The new facility expands the College's ability to provide training to more than 1,000 students per year and to offer more than 100 accredited courses. The forensic courses in the Identification of Unknown White-Powders, Soil Identification for Forensic Trace Evi- dence, Polarized Light Microscopy, Image Analysis, and Advanced Materials Analysis Techniques are among those in most demand. With the increased awareness after $9 / 11$ regarding terrorist threats, the importance of trace evidence in criminal investigative work is better understood. There has been an elevated interest in the microscopy field with the popularity of such television programs as CSI, Cold Case Files, Forensic Files, New Detectives, Medical Detectives, Nova, and offerings such as Court TV and the Discovery Channel.

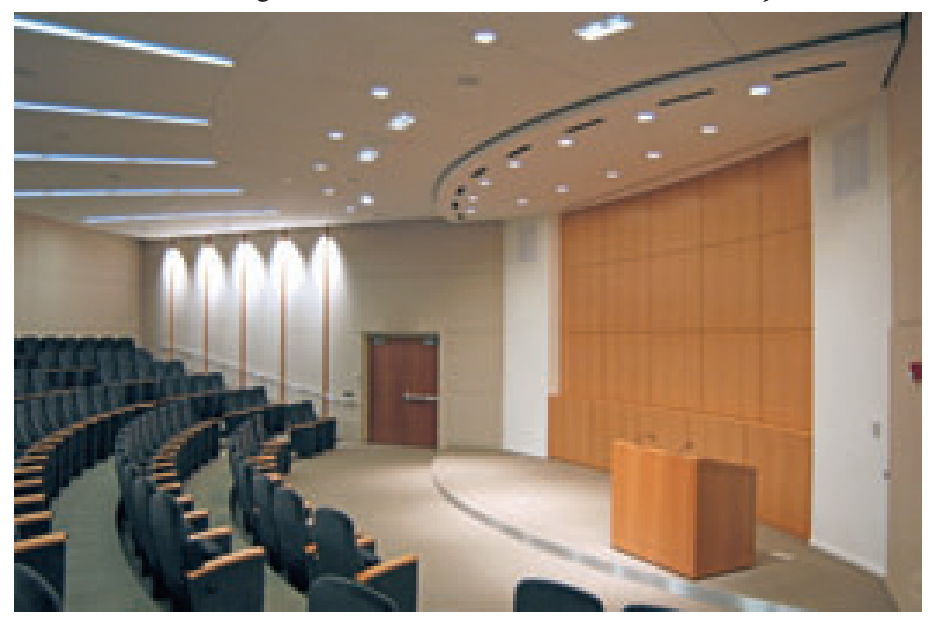

The new facility includes advanced microscopy equipment, "live" demonstration rooms, a library, and a 140-seat auditorium. The long-range plans for the College of Microscopy include offering formalized distance learning in 2008 and advanced degree programs beginning in 2010 .

McCrone's problem solving abilities have never been in greater demand. The building expansion was undertaken in July 2005 as a direct response to the urgent and rapidly growing requirements for microanalysis in the United States. We are directly addressing the increasing need for forensic and analytical services by first responders, forensics laboratories, pharmaceutical companies, and high school science programs across the country.

Government agencies have been increasingly tapping the company's expertise, particularly in areas of homeland security, seeking problem-solving capabilities in areas of homeland security in regard to weapons of mass destruction (WMD) and nanotechnology in materials development. The demand not only for quick responses to material problems but also for specialists in all areas of forensics science and materials analysis has grown significantly in the last five years.

With the continued threat and growing frequency of worldwide terrorist activity, the field of microscopy is emerging to be far more important than we predicted a decade ago, and it continues to be important as we move into the future. Microscopy is often referred to as the first line of defense when it comes to quickly and accurately identifying materials in situ. McCrone's scientists are actively engaged in solving an increasing number of the most challenging materials analysis problems, including contaminated products, manufacturing failures, and modern pharmaceutical drugs and life-saving products. The Group's team of scientists have traveled the world and lent their vast knowledge of analytical chemistry and microscopy skills to some of history's greatest mysteries such as the Shroud of Turin, Vinland Map, and Gospel of Judas to name just a few. The entire McCrone Group is dedicated to serving as an indispensable resource for educators, our clients and the scientific community. 